\title{
PRELIMINARY INVESTIGATIONS ON THE RED PIGMENT IN RICE AND ITS EFFECT ON GLUCOSE RELEASE FROM RICE STARCH
}

\author{
A.S. PERERA and E.R. JANSZ* \\ Department of Biochemistry, Faculty of Medical Sciences, University of Sri \\ Jayewardenepura.
}

(Received: 18 November 1999; accepted: 23 March 2000)

\begin{abstract}
Abstact: Rice (Oryza sutiva) containing a red pericarp is commonly advocated in local diets as it has a reputation of being more nutritive despite reports to the contrary that the red colour is only a pigment with no nutritive value.

This study shows that parhoiled red rice releases glucose more slowly on enzyme treatment than raw red rice of the same variety and also parhoiled white peric arped rice and raw milled white rice.

Studies on the red pigment confirmed that it was an anthocyanin but, not malvidin 3 -glucoside or eyanidin as previously reported. Its $\lambda$ max corresponded to pelargonidin. Further the anthocyanin appeared to be associated with protein. Trypsinization released the pigment. Sephadex gel chromatographgy also separated the pirment from protein. It appears possible that on parboiling the protein anthocyanin complex which, migrates in to the starch gel hy some mechanism inlihits enzyrnatic starch hydrolysis.
\end{abstract}

Key words: Anthocyanin, enzymatic starch hydrolysis, rice

\section{INTRODUCTION}

Rice (Oryza sativa) is the staple food of many Asian countries. Before rice goes to the market it is processed in a variety of ways. Paddy is dehulled raw by the process known as milling. The steps of processing may remove a part of the rice pericarp and aleurone layer, which contains a pigment and significant amounts of protein, fat, fiber, minerals and vitamins of the rice grain. This happens in dry milling and further losses occur in polishing. ${ }^{1}$ In an alternate method of processing ${ }^{2}$, parboiling preceeds milling. Here, paddy is heated in water to $60^{\circ} \mathrm{C}$. This causes gelatinization of starch. During this process the rice pericarp and aleurone layer are incorporated in to the rice grain. Red rice has an anthocyanin in its pericarp accounting for its colour.,

Ayurvedic as well as allopathic medical practitioners recommend raw red rice for diabetics. Even though there are no technical reports available, notable nutritionists of Sri Lanka have mentioned through newspaper reports that 'red' is only a pigment and does not have a nutritional function. Unfortunately, no systematic work has been done on this aspect previously until a recent report (1999)

* Corresponding author. 
stated that the parboiled red rice gives rise to a lower glycemic index than other rice types i.e. raw red rice, raw white rice and parboiled white rice. ${ }^{5}$ Surprising]y little has been done regarding the exact nature of the rice pigment. In some studies the red colour is referred to an anthocyanin imalvidin 3-glucoside or cyanidin ${ }^{4}$ ). It is possible that different rice varieties have different anthocyanins, which incidentally are widely disperised in plants and their colour affected by co-pigments. ${ }^{6,7}$ The objective of this study was to obtain some idea on the nature of the rice pigment and its effect on the in-vitro enzymatic release of glucose from boiled rice.

\section{METHODS AND MATERIALS}

Samples - Rice samples obtained from the Rice Research Institute station in Batalagoda was processed under standard conditions at the Rice Processing Research and Development Center, Anuradhapura. Rice of following varieties was used in this study.

White rice: $\mathrm{BG} 300$ (raw), $\mathrm{BG} 300$ (parboiled)

Red rice: BW 272.6 B (raw), BW 272.6 BP (parboiled)

Shaved white rice was used in preference to polished white rice in order to keep variety constant and to ensure that all red pigment was removed whole retaining as much as possible of the endosperm. This was done manually by carefully removing the red layer with a sharp blade.

\section{Studies on the pigment}

Extraction of the red pigment - Parboiled and raw red rice (1g) of the same rice variety (BW 272.6B) was added to ethanolic $\mathrm{HCl}$ ( $1.5 \mathrm{ml} 0.1 \mathrm{~N} \mathrm{HCl}+8.5 \mathrm{ml}$ ethanol) and allowed to stand for $24 \mathrm{~h}$ at $4^{\circ} \mathrm{C}$. The supernatant was decanted and centrifuged ( $2000 \mathrm{rpm}$ for $10 \mathrm{~min}$ ). Ethanol was evaporated to $3 \mathrm{ml}$. The absorption spectrum (400-700nm) was obtained using the double beam spectrophotometer (Shimadzu, UV-Visible spectrophotometer, model -UV-1601). The absorbances of extracts were routinely taken at $520 \mathrm{~nm}$.

Basification with $\mathrm{NH}_{3}$ with and without trypsinization - To the extract was added a few drops of conc. $\mathrm{NH}_{3}$. The precipitate formed was centrifuged at $2000 \mathrm{rpm}$ for 10 minutes. The absorption spectrum of the supernatant was obtained. The precipitate was redissolved in $0.1 \mathrm{~N} \mathrm{HCl}(3 \mathrm{ml})$ and the absorption spectrum of the solution obtained. The $\mathrm{pH}$ of the solution was adjusted to 7 and trypsin $(100 \mu \mathrm{l})$ added and the mixture incubated at $37^{\circ} \mathrm{C}$ for 15 minutes. After basification and centrifugation as above, the absorption spectrum of this solution too was obtained.

Paper chromatography of the trypsinized sample - n -Butanol : Acetone : Water (4:1:5) was used as solvent system. The top layer (butanol saturated with acetone) 
was separated and used as the non-polar mobile phase. Ascending chromatography

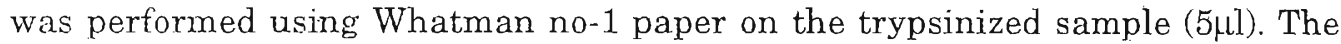
paper was visualized with $1 \%$ ninhydrin in acetone spray after drying at $100^{\circ} \mathrm{C}$ for 2-3 minutes.

Gel chromatography - Sephadex G-100 gel ( $5 \mathrm{~g}$ ) was soaked in 0.1M phosphate buffer $(\mathrm{pH} 7,200 \mathrm{ml})$ for $72 \mathrm{~h}$ for swelling, and packed in a column (height-16 $\mathrm{cm}$ and diameter- $2 \mathrm{~cm}$ ). The void volume was determined using dextran blue ( $1 \mathrm{mg}$ in $0.5 \mathrm{ml}$ ). The pigment extract was evaporated to $1 \mathrm{ml}$ and the $\mathrm{pH}$ adjusted to 7 and introduced to the column. After the void volume eluted, $2.5 \mathrm{ml}$ fractions were collected in constant intervals with a time-based fraction collector (flow rate $-2.5 \mathrm{ml}$ per $12 \mathrm{~min}$ ). The column was run for $12 \mathrm{~h}$. The absorbance of all fractions was read at $280 \mathrm{~nm}$ and at $520 \mathrm{~nm}$. The coloured samples were combined and freeze-dried.

Folin. Ciocalteau phenol reagent test for proteins ${ }^{8}$ - The test was conducted for both the colourless and coloured fractions.

\section{Estimation of rate of starch digestion of different types of rice}

Enzymatic hydrolysis - Rice specimens were boiled until cooked for about 20 minutes. Samples (1g) were homogenized, and heated for 10 minutes at $100^{\circ} \mathrm{C}$ with Hitempase $(20 \mu 1$ ), (a heat stable $\alpha$ amylase from Bacillus licheniformis, Quest, 1140units $\mathrm{ml}^{-1}$ ) after adjusting the $\mathrm{pH}$ to 7 . The $\mathrm{pH}$ was then adjusted to 5.0 and

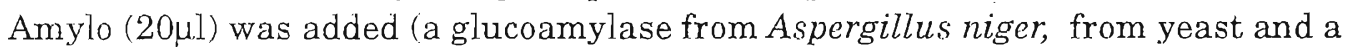
1-6 glucano glucan, Quest, 1100 units $\left.\mathrm{ml}^{-1}\right)$ and kept at $55^{\circ} \mathrm{C}$. Samples $(1 \mathrm{ml})$ were collected at $45 \mathrm{~min}$ and then in $1 \mathrm{~h}$ intervals. To determine the complete hydrolysis, larger quantities of enzymes were used (0.2ml Hitempase and $1 \mathrm{ml}$ Amylo) and incubated at $55^{\circ} \mathrm{C}$ for a longer time $(6 \mathrm{~h})$.

Assay of reducing sugars by the Nelson method" - Using Nelson method, glucose was estimated in the samples. The Nelson method gave a linear standard curve with an $R^{2}$ value of 0.99 with a c.v. for the various concentrations $5-10 \%$ (an

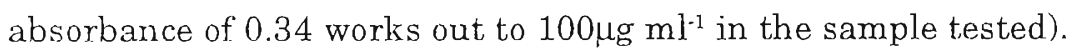

\section{RESULTS}

\section{The pigment}

It was found that the pigment of red parboiled rice was very difficult to extract in ethanolic $\mathrm{HCl}$ (anthocyanin extracting solvent) compared to raw red rice. This was probably due to either binding or the texture of rice. Homogenized parboiled red rice (BW 272.6BP) released only 20-25\% of the pigment released by raw red rice of the same variety on extraction with ethanolic $\mathrm{HCl}$. Absorbance was measured at the $\lambda \max$ of $520 \mathrm{~nm}$. 
On extraction of the pigment from raw red rice with methanolic $\mathrm{HCl}$ and obtaining UV spectrum, a $\lambda$ max of $520 \mathrm{~nm}$ was observed. On basification with $\mathrm{NH}_{3}$ the coloured substance precipitated with a large amount of other components. The supernatant gave a slight yellow colour with a $\lambda \max$ of $470 \mathrm{~nm}$. The acidification of the precipitate gave back the red colour with a $\lambda$ max of $520 \mathrm{~nm}$. Addition of trypsin to the precipitate at $\mathrm{pH} 7$ resulted in the colour being released from the solid material. On basification the supernatant still gave a red colour with a $\lambda \max$ of $580 \mathrm{~nm}$ without giving any precipitate. The red colour became lighter when sodium metabisulphite ( $5 \mathrm{mg}$ ) was added as expected for anthocyanins being irreversible with excess metabisulphite. ${ }^{10-13}$ These absorption maxima do not correspond to cyanidin $(\lambda \max -535 \mathrm{~nm})$ or malvidin 3 -glucoside $(\lambda \max -550 \mathrm{~nm}) .{ }^{10}$ The solution resulting from trypsinization, paper chromatography and ninhydrin spray yielded a streak of ninhydrin positive purple with a dark purple spot just moving above the origin.

Following gel chromatography the red colour was obtained only at eluent volume of $40 \mathrm{ml}$ after the void volume. The fractions before this showed a slight consistent absorption at $280 \mathrm{~nm}$ and mildly positive for the Folin Ciocalteau test. The red pigment gave a strong Folin Ciocalteau positive reaction.

\section{Location of pigment in processed rice}

In raw red rice the pigment is in the outer pericarp and can easily be extracted in ethanolic - HCl. In parboiled red rice the pigment has impregnated the gelatinized starch which has been subsequently dried. The grain is glassy with the red pigment being found in the starchy gel. It is not possible to extract the red pigment quantitatively even after powdering. Therefore the extent of red pigment in raw red and parboiled red cannot be compared. However this does not affect the final conclusion.

\section{Rate of starch digestion of different types of rice}

The glucose release from parboiled red rice is much slower initially when compared to raw red rice, raw white rice and parboiled white rice (Fig. 1). Shaving the red layer from raw red rice had no effect compared to raw red rice but both raw types showed higher initial glucose release (1-2h) compared to parboiled red rice. This shows that the red pigment had no effect on glucose release if there was no parboiling to transfer it into the starch gel (Fig. 2). Using larger amounts of enzyme, total glucose release was found to be similar at the end of $6 \mathrm{~h}$ indicating comparable glucose release in the 4 types of rice. 


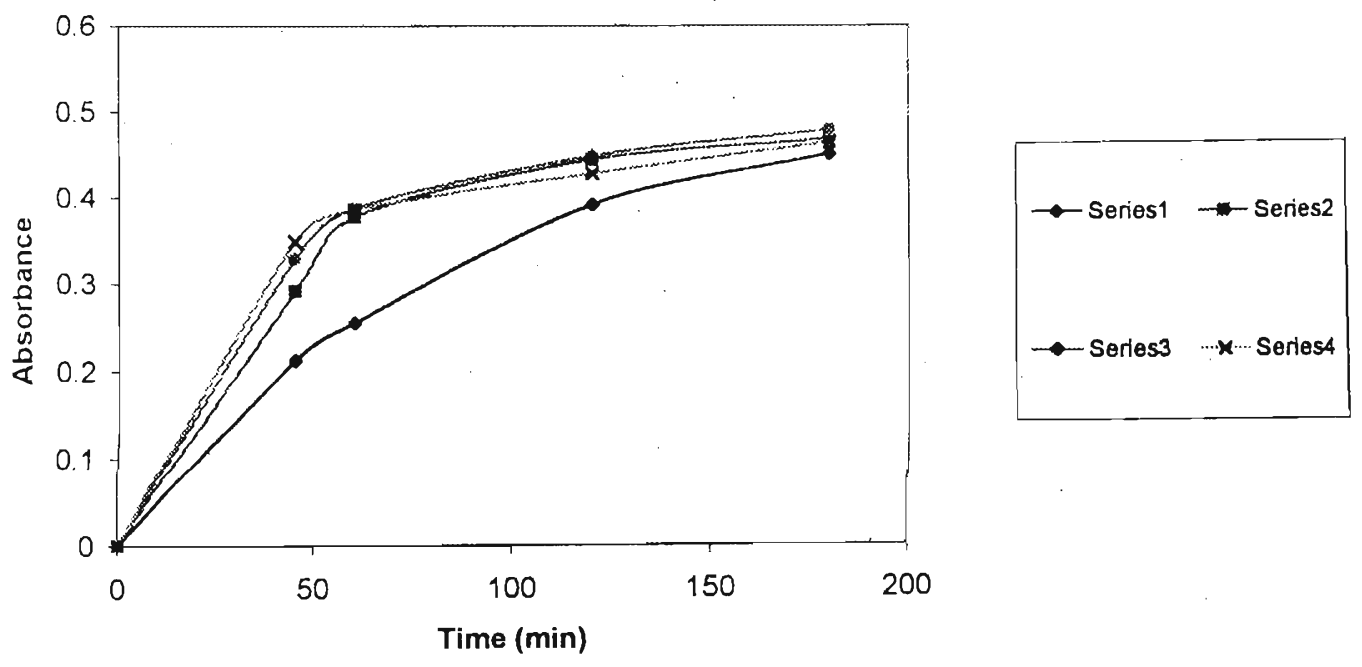

Figure 1: Rate of release of glucose with varying rice type

[ $\mathrm{a}$ Kaw red rice; - Parboiled red rice; $\mathrm{X}$ raw white rice; 0 parboiled white rice. Total release corresponded to a calculated absorbance of $10.0 .469,0.452,0.465$ and 0. 4.79 respectively for the 4 types of rice.

\begin{tabular}{|c|c|c|}
\hline Series 1 & - Series2 & 口Series3 \\
\hline
\end{tabular}

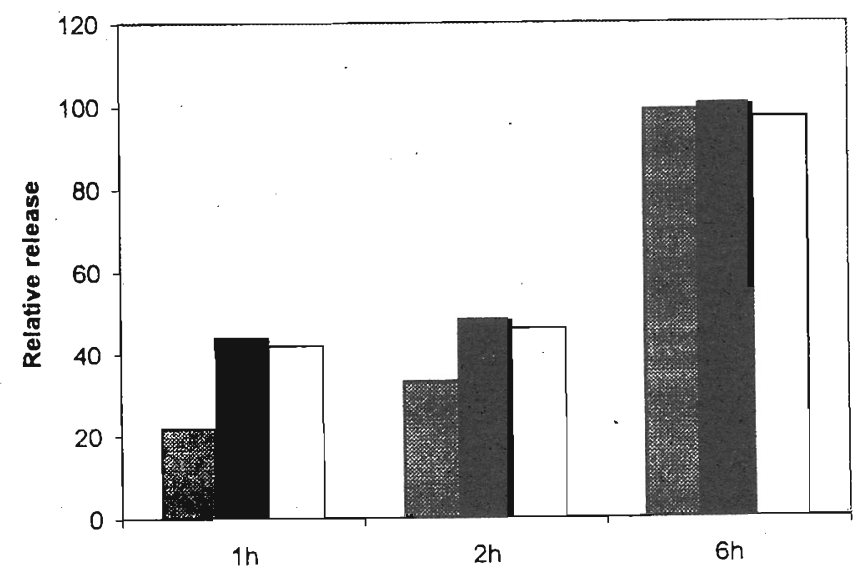

Higure 2: Comparative release of glucose from $\square$ raw red rice; $\square$ parboiled red rice, $\square$ shaved raw red rice. 


\section{DISCUSSION}

The above experiments confirm that the red pigment is an anthocyanin. But $\lambda$ max values from this rice variety indicate that it is not cyanidin or malvidin 3-glucoside and possibly pelargonidin because its $\lambda$ max was $520 \mathrm{~nm}^{7.11}$ Its colour also disappeared with treatment with sodium metabisulphite. ${ }^{10}$ Precipitation in alkaline medium initially was a puzzle as anthocyanins are more soluble in basic medium. From the bulk of the precipitate it was assumed that the anthocyanin was in some way attached to a macro-component.This appears valid as trypsinization liberated the anthocyanin, which was then soluble in basic medium. Paper chromatography of the trypsinized sample showing degradation products of proteins further supported this finding. Gel chromatography indicated that the binding of the pigment to protein was weak as the pigment eluted separately from protein. The positive Folin Ciocalteau can be due to reaction of the red pigment with phenolic groups of the anthocyanin.

It has not been possible to compare the relative content of red pigment in raw and parboiled red rice.

In-vitro enzyme hydrolysis experiments clearly (fig. 1 and Fig. 2) show that a combination of parboiling and presence of red pigment causes a slower release of glucose. This is consistent with the finding that parboiled red rice has the lowest glycemic index of the rice types studied. ${ }^{5}$ This can be due either to simple nonspecific polyphenolic inhibition ${ }^{14}$ of $\alpha$ amylase or by protein-anthocyanin linked steric factors (recalling that rice starch contains a protein coat). It, is possible that parboiled red rice has more anthocyanin than raw red rice but the authors do not believe that this is major factor.

These studies are preliminary and it could be argued that if mammalian enzymes were used the results could be different. However recent studies ${ }^{1 ;}$ show that a similar result was manifested using pancreatic $\alpha$-amylase. This study shows that the red pigment inhibits even the more rugged microbial enzymes. It is speculated that the protein-pigment complex, by a mechanism not completely understood, permeates the starch gel in parboiling and inhibits in-vitro enzymatic hydrolysis. The fact that the same variety of rice was used in the case of parboiled and raw milled rice confirmed that the change occurred as a result of processing techniques and not variety. Further that both the red pigment and parboiling is necessary to slow glucose release.

The inhibition of enzyme hydrolysis of starch in the presence of rice pigment of parboiled rice could provide the biochemical basis for the beneficial effects of parboiled red rice. However, clearly more work has to be done. 


\section{Acknowledgement}

The authors thank the Rice Research Institute, Bathalagoda and Dr. P. Hettiarachchi for rice samples and the IPICS - SRI: 07 grant for chemicals.

\section{References}

1 Wikramanayake T. W. (1996). Food and Nutrition. Hector Kobbekaduwa Agricultural Research Institute 150-156pp

2 Ali. N and Odja J. P.(1976). Rice post harvest technology -Parboiling. IDRC, Canada 163-204.

3 Markakis P. (1982). Anthocyanins as food colours. Academic Press London $153 \mathrm{p}$

4 Maekawa M. (1998). Recent information on anthocyanin pigmentation. Rice Genetics Newsletter. 13:25-26.

5 Hettiarachchi P., Jiffry M. T. M., Jansz E. R. \& Fernando D. (1999). Proceedings of $3 r d$ Annual Sessions of Faculty of Medical Sciences, University of Sri Jayewardenepura FP11.

6 Hendry G. A. F. \& Houghton J. D. (1992). Natural Food Colourants. AVI Publ. Company, New York, USA 183-217pp

Harbourne J. B. (1967). Comparative biochemistry of the flavonoids. Acad. Press Lond. UK.

8 Nelson N. (1944). A Photometric adaptation of the somogyi method for determination of glucose. Journal of Biological Chemistry 153:375-380.

9 Lowry O.I-., Rosebrough W.J., Farr A.L. \& Randall R.J. (1951). Protein measurement with Folin phenol reagent. Journal of Biological Chemistry $193: 265-275$.

1.) Markakis P. (1974). Anthocyanins and their stability in food. CRC critical reviews in food technology $437-456 \mathrm{pp}$

11 Bakku J. \& Birdle P. (1992). Strawberry juice colour; The effect of Sulphur dioxide and EDTA on stability of Anthocyanins. Journal of Science of Food and Agriculture. 60: 477-481. 
12 Simpson K. L. (1985). Chemical changes in food processing. AVI Publishing Company, New York, USA 426-433pp

13 Hulme A. C. (1971). The biochemistry of fruits and their products. Vol 2 Academic Press London UK 711-712pp

14 Ekanayake S. (1999). Nutritional value and antinutritional factors in Canavalia gladiata. MPhil thesis, University of Sri Jayewardenepura $131-133 \mathrm{pp}$

15 Thadhani V.M., Jansz E.R. \& Peiris H. (2000). Effect of pancreatic amylase on hydrolyses of rice and wheat starch processed in different ways. Chemistry in Sri Lanka 17 (2) 